\title{
Erratum to: Density dependence in the thermal conductivity of cellulose fiber mats and wood shavings mats: investigation of the apparent thermal conductivity of coarse pores
}

\author{
Noboru Sekino ${ }^{1}$
}

Published online: 30 November 2015

(C) The Japan Wood Research Society 2015

\section{Erratum to: J Wood Sci}

\section{DOI 10.1007/s10086-015-1523-6}

Owing to an unfortunate oversight on the part of Publisher, Figs. 3 and 5 were published with errors in the initial publication of the article. The corrected Figs. 3 and 5 are published with this erratum.

The online version of the original article can be found under doi:10.1007/s10086-015-1523-6.

Noboru Sekino

sekino@iwate-u.ac.jp

1 Faculty of Agriculture, Iwate University, Morioka 020-8550,

Japan

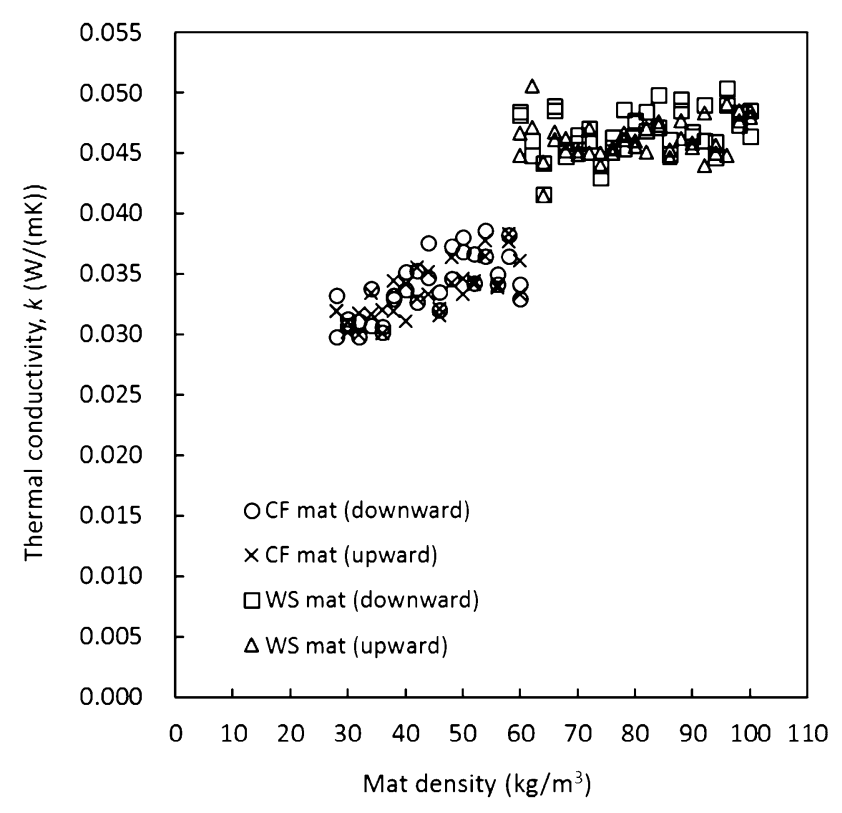

Fig. 3 Relationships between mat density and thermal conductivity, $C F$ cellulose fiber, $W S$ wood shavings 


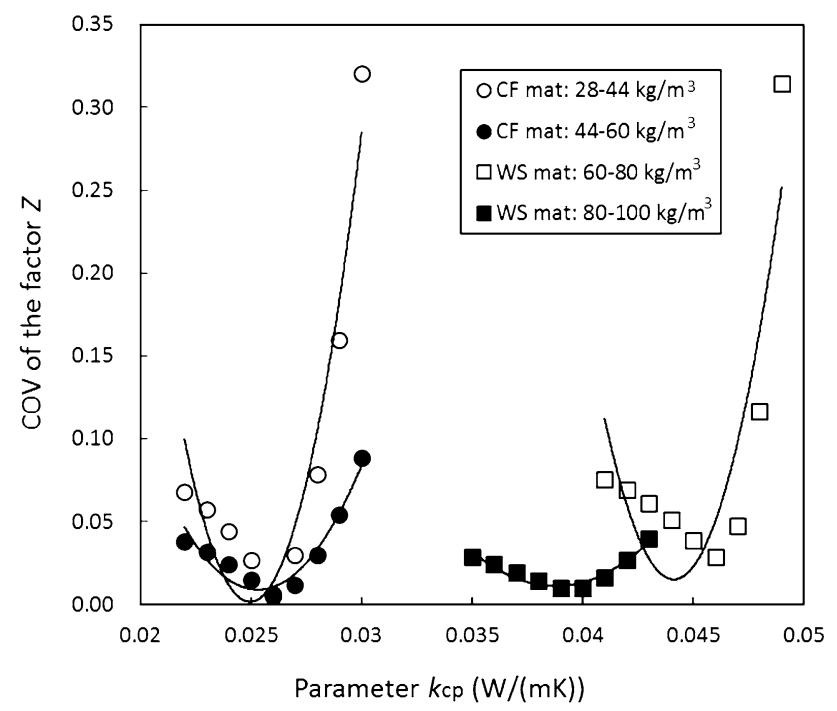

Fig. 5 Relationships between the parameter $k_{\mathrm{cp}}$ and the coefficient ofvariance $(\mathrm{COV})$ of factor $Z$ 